\title{
Numerical Analysis of Contact Area under Slippage Conditions
}

\author{
Marwah Sabah Fakhri \\ Mechanical Engineering, Re-construction and Projects Directorate, Ministry of Higher \\ Education and Scientific Research/Baghdad-Iraq. \\ marwasabah85@yahoo.com \\ Ihsan A. Baqer \\ Department of Mechanical Engineering,University of Technology/Baghdad-Iraq \\ 20007@uotechnology.edu.iq
}

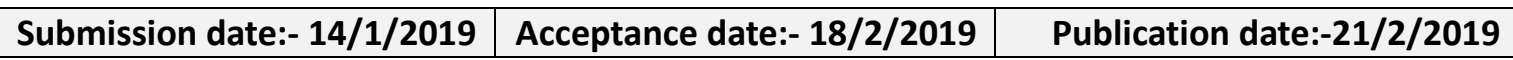

\begin{abstract}
In the present paper, the contact of area, which is produced between a pair of bodies (flat surface and hemi-cylindrical shape), has been studied under the effect of slippage occurrence, where it represents one of the important problems in the mechanical engineering, especially in robotic design. Many parameters have been studied, like frictional forces, equivalent stresses, friction coefficient, and contact area of deformation. The behavior of these parameters has been monitored during the slippage that is generated between the flat surface made from cast alloy steel and the other part made from rubber. The finite element method (FEM) with SOLIDWORKS software was used to simulate this contact area under the slippage effect. The results of the simulation showed a significant behavior, particularly at the beginning of slippage and the stage of (stick-slip) phenomena, in other words, the simulation outputs indicated that the slippage influence has an important behavior, especially when the phenomena of both slippage and stick-slip stage start to occur. These analyses are intended to understand how the contact area affected to design measures to prevent the slippage occurrence and the damage in contacted bodies.
\end{abstract}

Keywords: Contact area, Slippage phenomena, Viscoelastic contact, Stress analysis, Friction force.

\section{Terminology:}

\begin{tabular}{|c|l|c|}
\hline Symbols & Definition & Units \\
\hline A & Rectangular contact area of hemi-cylindrical object & $\mathrm{mm}^{2}$ \\
\hline $\mathrm{a}$ & Half of contact area width & $\mathrm{mm}$ \\
\hline $\mathrm{b}$ & Half of contact area depth & $\mathrm{mm}$ \\
\hline $\mathrm{E}$ & Young's Modulus & $\mathrm{GPa}$ \\
\hline Et & Tangent modulus & $\mathrm{MPa}$ \\
\hline $\mathrm{FEM}$ & Finite Element Method & - \\
\hline $\mathrm{F}_{\mathrm{n}}$ & Perpendicular (normal) force & $\mathrm{N}$ \\
\hline $\mathrm{F}_{\mathrm{t}}$ & Tangential force (friction force) & $\mathrm{N}$ \\
\hline $\boldsymbol{\mu}$ & Friction coefficient & - \\
\hline $\mathcal{V}$ & Poisson's ratio & - \\
\hline $\mathrm{X}$ & Displacement of slippage & $\mathrm{mm}$ \\
\hline$X^{\cdot .}$ & The acceleration of slippage & $\mathrm{m} / \mathrm{s}^{2}$ \\
\hline$\sigma \mathrm{y}$ & Yield stress & $\mathrm{MPa}$ \\
\hline$\sigma_{\mathrm{zz}}$ & The stress component perpendicular to the surface of contact & $\mathrm{Pa}$ \\
\hline
\end{tabular}




\section{Introduction:}

Due to the specific importance of the frictional contact in machines, the phenomenon of slippage has converted into one of the important topics in robotic hand design and other uses, for example, rubber ball on a surface and tire on a surface. The studies of the phenomenon of slippage lead to the proper design of fingertips and then produce a stable grasp. In this field, [1] studied the mechanics of contact using modeling theoretically beside validation experimentally. It was assumed that the anthropomorphic smooth finger materials are nonlinear elastic, also the relation between the contact area radius and the perpendicular force was derived. [2] Presented a precise FEM solution for the elastic-plastic contact between a rigid flat and a deformable sphere through utilizing constitutive laws suitable for every deformation mode either is plastic or elastic. [3] focused on the perpendicular force influence on the slippage while feeding the medium, and evolved a 2D simulation model for a system of paper feeding, then slippage was computed for different normal forces. [4] Presented the effects of skin hydration on the contact mechanics for soft fingers for reducing the contact tendency to slip, without taking into account the coefficient of friction changes, because the grips were highly unsteady under the states of dry skin. [5] considered a FEM depending upon the analysis of contact of an elastic-plastic axisymmetric hemisphere and employing ANSYS for studying the material characteristics influence under the state of a completely stick contact. Thus, the aim was to study the influence of the elasticity modulus (E), the yield stress (Y) and the ratio of (E/Y) on the contact variables, such as the area of contact, the pressure of contact and the load of contact under the states of a completely stick contact. [6] Introduced a proper modeling of a visco-elastic contact that is able to cover the contacts analysis to meet the non-permanent and elastic contacts responses.

[7] Set the force sensors and the optical slip sensors on a cuff, which were utilized for measuring multiple kinds of contact data, including the relative displacement between the human skin and the cuff, slippage and the force of interaction.

These measurements and the contact behavior analyses, comprising the slippage direct measurement, can be contributed to the development of a model of contact that is beneficial for enhancing the regulations of contact safety.

In the present study, the area of contact, which is produced between a pair of bodies (flat surface and hemi-cylindrical shape), has been studied numerically by utilizing the commercial software (SOLIDWORKS) under the effect of slippage occurrence. Many parameters have been studied, like frictional forces, equivalent stresses, friction coefficient, and contact area of deformation.

\section{Experimental Work:}

Laboratory tensile tests for rubber were used to know the properties experimentally. The tensile test was done with the specimen of dimensions shown in figure (1) [8] in the university of technology/ mechanical engineering department laboratories. The rubber tensile specimen was prepared by special laser tool to get the accurate profile with exact required dimension.

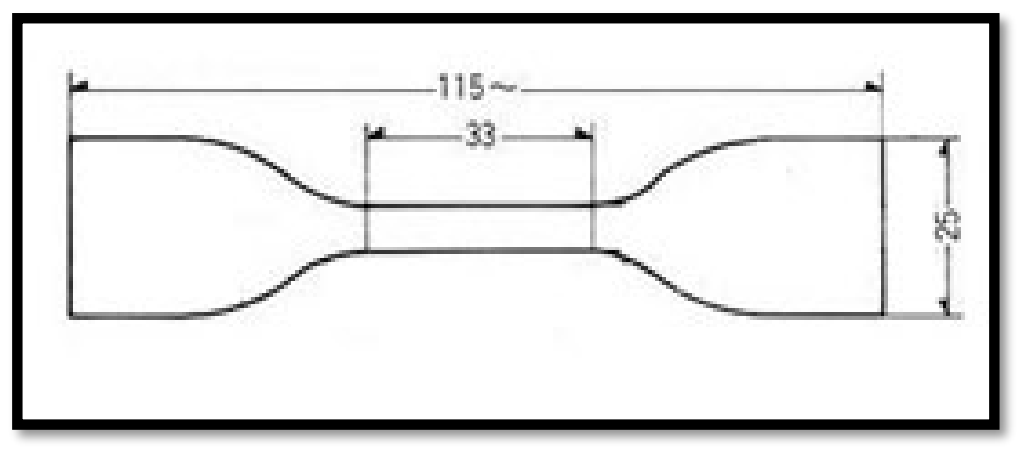

Fig (1) : Specimen of dimensions for rubber [8] 
For cast alloy steel, the properties of ASTM A217 are shown in the table below [9]. All the data (experimantal and standard) were used as input to SOLIDWORKS software.

Table (1): Mechanical properties for rubber and cast alloy steel

\begin{tabular}{|c|c|c|c|c|}
\hline \multicolumn{2}{|c|}{ Material } & $\begin{array}{c}\text { Young's Modulus, E } \\
(\text { GPa })\end{array}$ & $\begin{array}{c}\text { Yield strength, } \boldsymbol{\sigma}_{\mathbf{y}} \\
(\mathbf{M P a})\end{array}$ & $\begin{array}{c}\text { Poisson's } \\
\text { ratio, } \boldsymbol{V}\end{array}$ \\
\hline Rubber & Experimental & $\mathbf{2 5}$ & $\mathbf{1 0}$ & $\mathbf{0 . 4 8}$ \\
\hline $\begin{array}{c}\text { Cast alloy } \\
\text { steel }\end{array}$ & Standard & $\mathbf{1 9 0}$ & $\mathbf{2 7 0 - 4 6 0}$ & $\mathbf{0 . 2 8}$ \\
\hline
\end{tabular}

\section{3 - Modelling of Contact Area}

In this study, a nonlinear material model with a mechanics of contact is represented. In the following, the derivation of relation between the contact area width and the perpendicular (normal) force for the contacts of a hemi-cylindrical object with a flat surface, as shown in the figure (2):

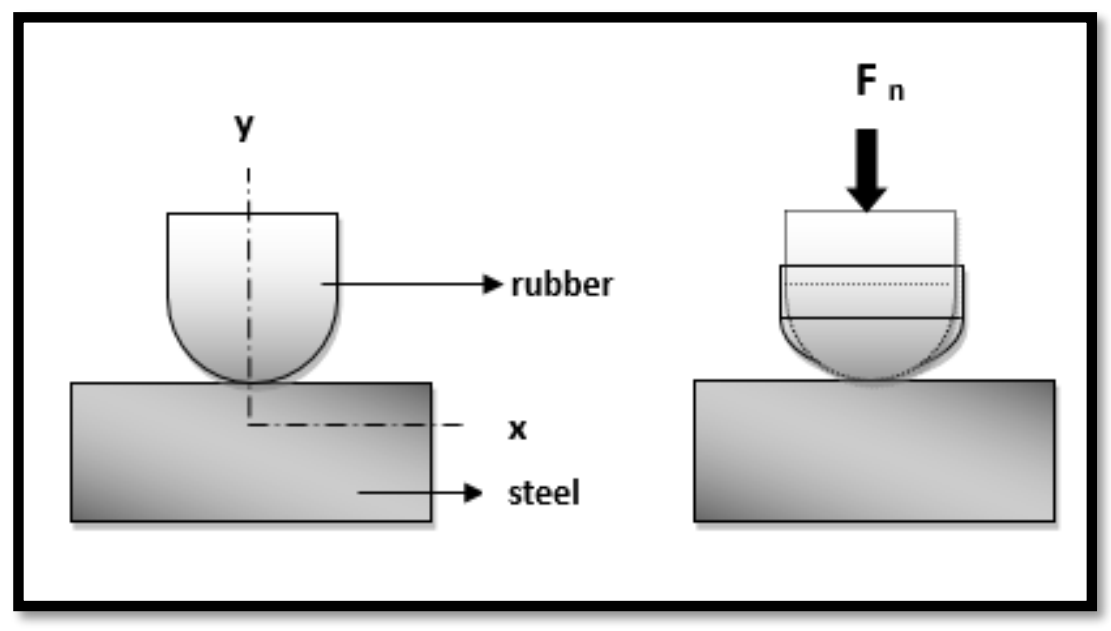

Fig (2): Model of the non-linear elastic hemi-cylinder contacting flat surface

The balance of forces for the contact area in the y direction can be written as [1]:

$$
\Sigma \mathrm{Fy}=0
$$

$$
\mathrm{F}_{\mathrm{n}}=\int_{\mathrm{a}}^{a^{-}} \sigma_{\mathrm{ZZ}} d A
$$

In this work, $d A$ is the rectangular contact area of a hemi-cylindrical object, (assuming the depth (2b) is remaining constant), as shown in figure (3).

Equation (2) represents a relation between the perpendicular (normal) force and the area of contact without considering the influence of slippage.

$$
F_{n}=\int_{-b}^{b} \int_{-a}^{a} \sigma_{Z Z} d x d y=2 b \int_{-a}^{a} \sigma_{Z Z} d x
$$

The friction force is generated owing to the slippage (displacement) of the hemi-cylinder object along the direction that is parallel to the flat surface. In the other words, the hemi-cylindrical object is accelerated to slide on the flat surface and then this generates the friction force, as depicted in equations (3, 4 and 5).

$$
\begin{aligned}
& \sum \mathrm{Fx}=\mathrm{M} X^{*} \\
& \mathrm{~F}_{\mathrm{t}=\mathrm{M} X^{*}}
\end{aligned}
$$


Where:

$$
F_{t}=\mu F_{n}
$$

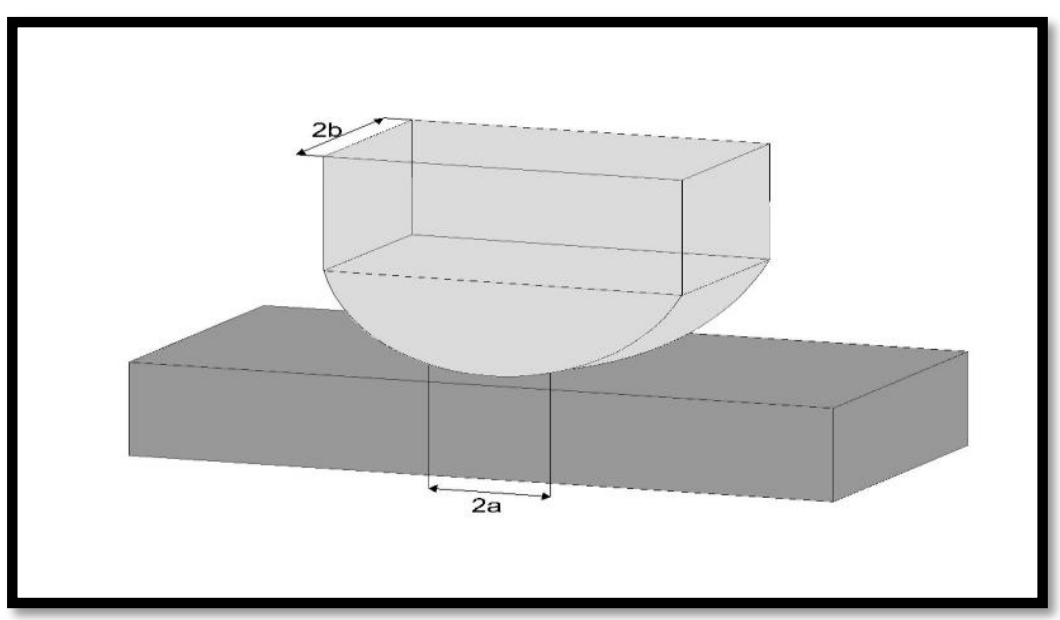

Fig (3): Model of flat and hemi-cylindrical surfaces

Therefore, in this paper, the analysis of finite element was utilized for simulating the stress and deformation of contacts area between the two bodies, one was flat with fixed surface and the other was sliding viscoelastic hemi-cylindrical shape which is made from a rubber material, as shown in figure (4).

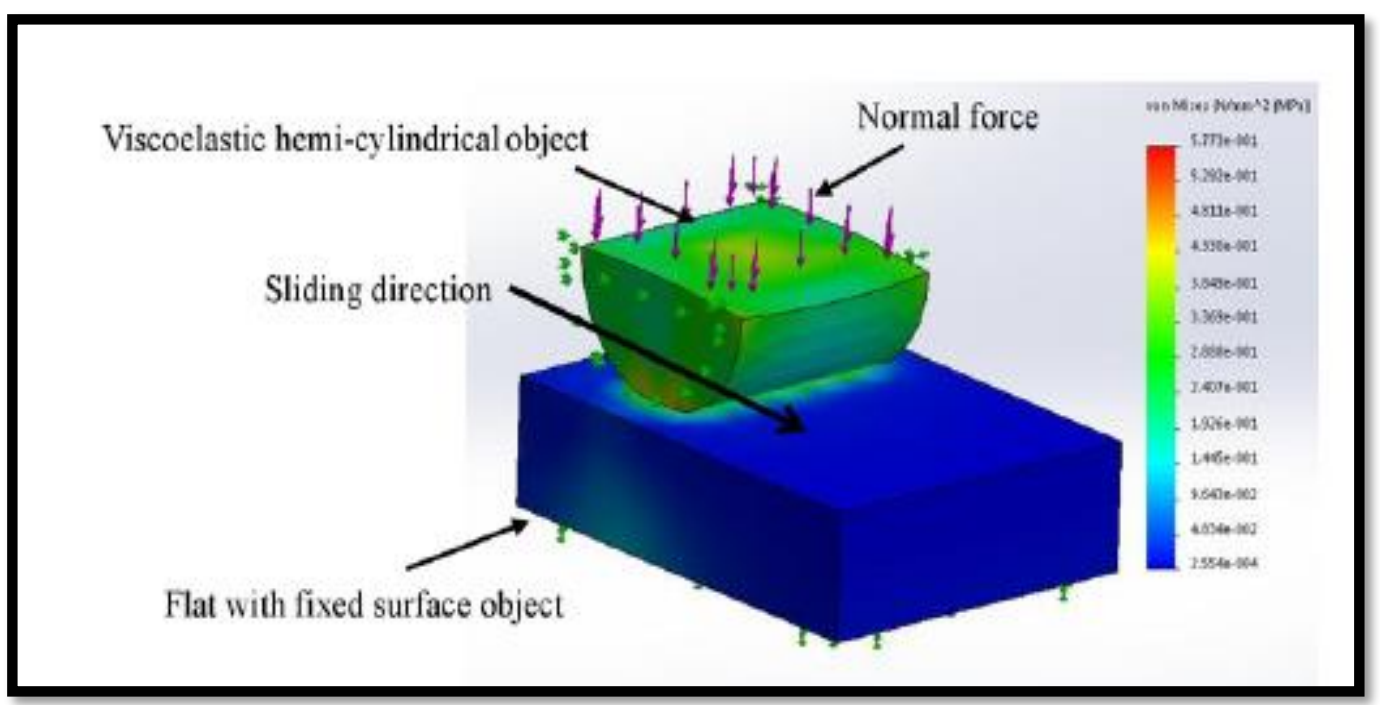

Fig (4): A model of FEA with SOLIDWORKS software.

The simulation of the contact area involved many variables (coefficient of fraction, $\mu$, force of friction, and external exerted normal force). Four cases have been studied in this research as shown in table (2) below and will be described in the following sections. 
Table (2): All cases in this work

\begin{tabular}{|c|c|c|}
\hline Case & Inputs (values $\mathbf{F}$ and $\boldsymbol{\mu}$ ) & Outputs \\
\hline 1 & $\begin{array}{l}F=80 \mathrm{~N}(\text { constant }), \text { friction coefficient }=0.1,0.3,0.5,0.7,0.9 \\
F=90 \mathrm{~N}(\text { constant }), \text { friction coefficient }=0.1,0.3,0.5,0.7,0.9 \\
F=100 \mathrm{~N}(\text { constant }), \text { friction coefficient }=0.1,0.3,0.5,0.7,0.9\end{array}$ & \multirow[b]{2}{*}{ Stresses $(\mathrm{MPa})$} \\
\hline 2 & $\begin{array}{l}\text { Friction coefficient }=0.3(\text { constant }), \text { force }=80,90,100 \mathrm{~N} \\
\text { Friction coefficient }=0.5(\text { constant }), \text { force }=80,90,100 \mathrm{~N} \\
\text { Friction coefficient }=0.7(\text { constant }), \text { force }=80,90,100 \mathrm{~N} \\
\text { Friction coefficient }=0.9(\text { constant }), \text { force }=80,90,100 \mathrm{~N}\end{array}$ & \\
\hline 3 & $\begin{array}{l}F=80 \mathrm{~N}(\text { constant }), \text { friction coefficient }=0.1,0.3,0.5,0.7,0.9 \\
F=90 \mathrm{~N}(\text { constant }), \text { friction coefficient }=0.1,0.3,0.5,0.7,0.9 \\
F=100 \mathrm{~N} \text { (constant), friction coefficient }=0.1,0.3,0.5,0.7,0.9\end{array}$ & Friction force $(\mathrm{N})$ \\
\hline 4 & At $\mathrm{F}=0,80,90,100 \mathrm{~N}$ and $\mu=0.9$ & $\begin{array}{l}\text { Deformation area } \\
\left(\mathrm{mm}^{2}\right)\end{array}$ \\
\hline
\end{tabular}

\section{4 - Results and Discussion:}

\section{$\underline{4.1}$ - Case 1}

This case involved studying the influence of friction coefficient that varies, on equivalent stress of von Mises, with the specific normal forces (80, 90, and 100) $\mathrm{N}$ on the slipped object. Figures (5, 6 and 7) show the von Mises stress behavior under the normal force (80) N with (5) various friction coefficient $(\mu)$ values $(0.1,0.3,0.5,0.7$, and 0.9$)$. So, the increasing in the coefficient of friction leads to increasing the equivalent stress, except that at value of $\mu(0.1)$ since no significant change in the stress with time when ( 80 and 90) $\mathrm{N}$ normal forces are applied (see figures 5 and 6). But, at $100 \mathrm{~N}$ applied normal force as shown in figure (7), the result reveals a clear change in the stress value at $(\mu=0.1)$ because of the increasing of frictional force as a consequence of normal force increasing. The friction coefficient values from 0.3 up to 0.9 , and the time interval of the slip $(0-0.2)$ Sec depicted the jump in stress magnitude and then dropped down, this phenomenon is occurring due to the transmitting from the static friction to dynamic friction as presented by [10].

Another significant phenomenon is the oscillation in stress values after the period of friction mode transmission; this phenomenon represents the slip-stick occurrences that generate a microvibration in moving objects [11]. 


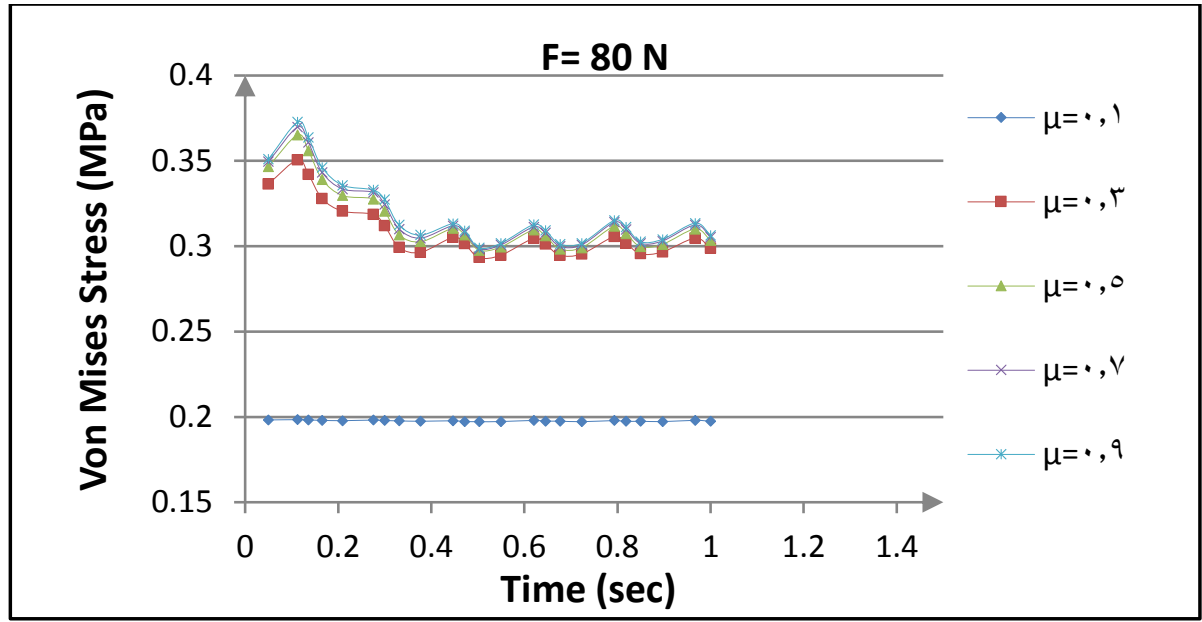

Fig (5) Von Mises stress behavior at $80 \mathrm{~N}$ force

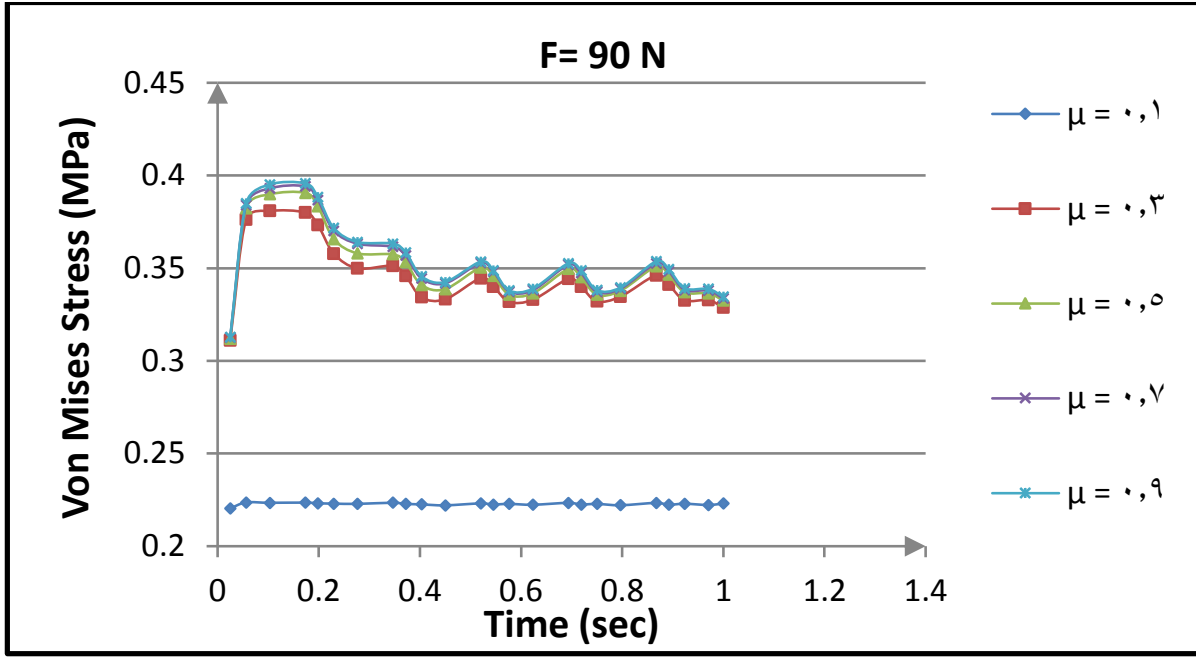

Fig (6) Von Mises stress behavior at $90 \mathrm{~N}$ for

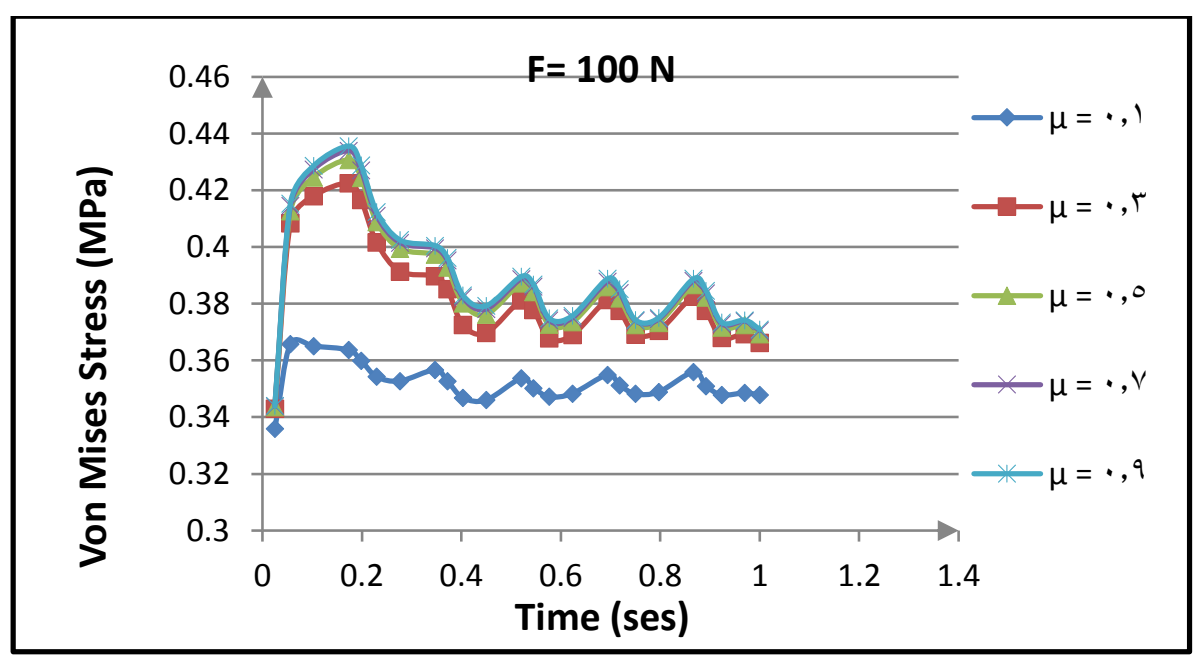

Fig (7) Von Mises stress behavior at $100 \mathrm{~N}$ force

\section{2 - Case 2}

In this case, the stress behavior of the contacted area was studied under the effect of three normal forces $(80,90$, and 100$) \mathrm{N}$ with a constant coefficient of friction. 
Figures $(8,9,10$ and 11) display the low effect of the coefficient of friction that varies in comparison with the effect of normal force. Also, the slope of stress, after transmitting in friction mode (transition from static to kinetic friction behavior) [12], is decreased with increasing in the coefficient of friction value.

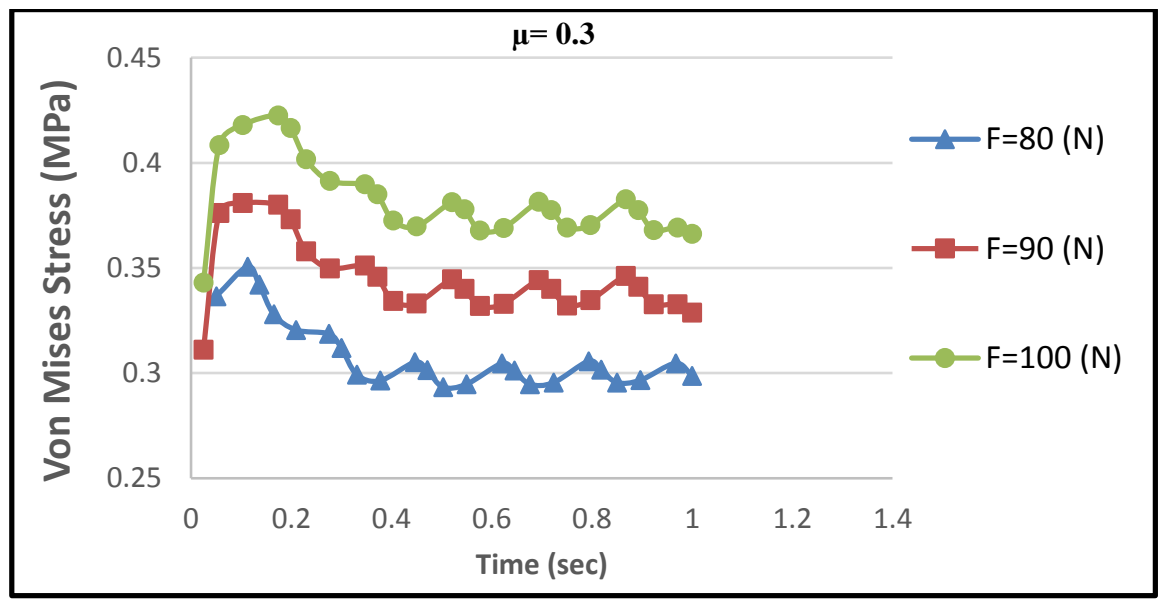

Fig (8) Von Mises stress behavior at $\mu=0.3$

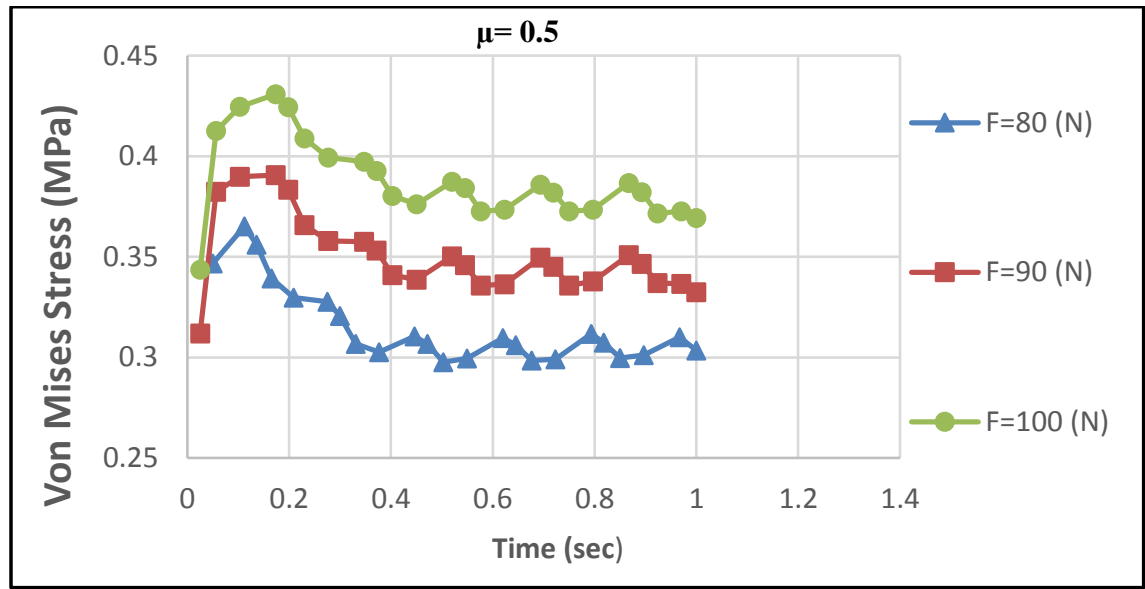

Fig (9) Von Mises stress behavior at $\mu=0.5$

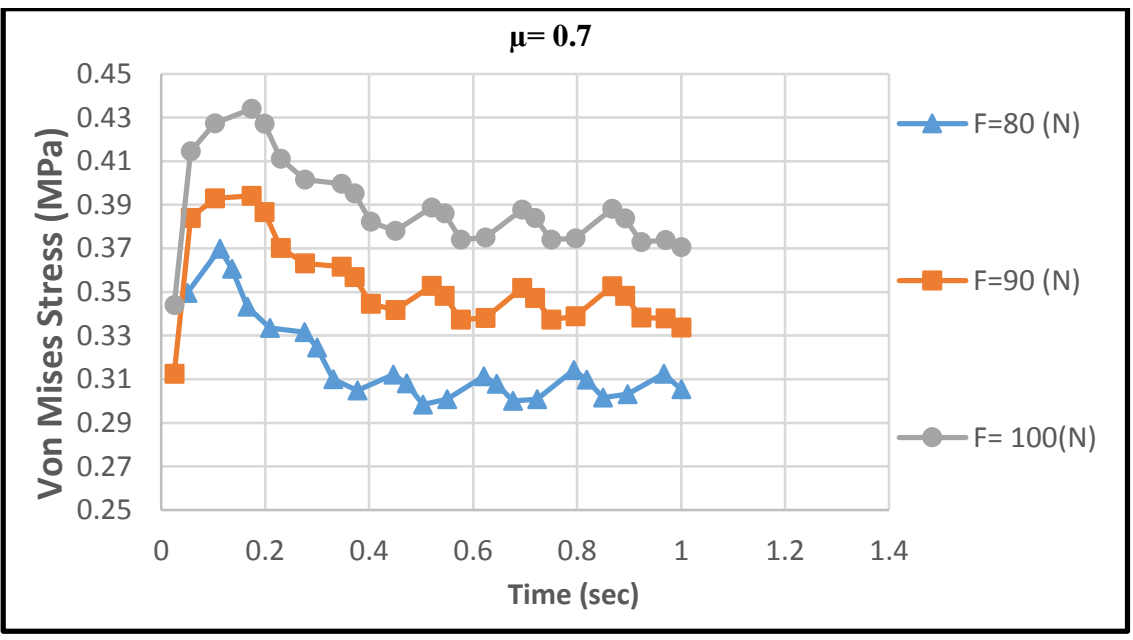

Fig (10) Von Mises stress behavior at $\boldsymbol{\mu}=0.7$ 


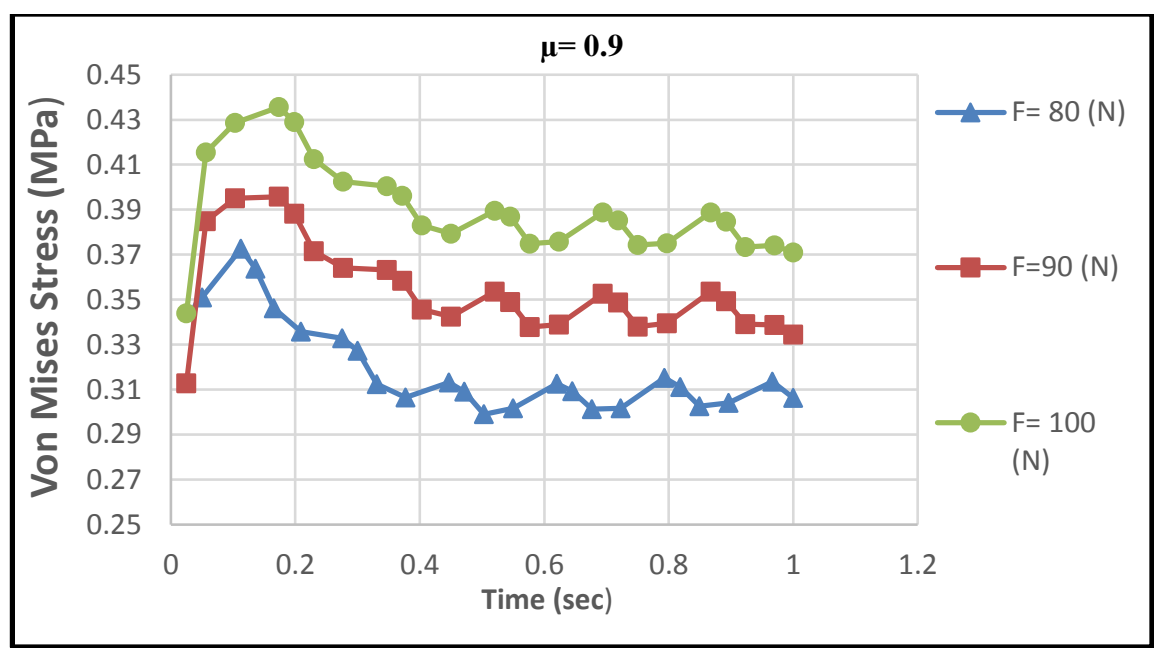

Fig (11) Von Mises stress behavior at $\mu=0.9$

\section{3 - Case 3}

In this case, the frictional force was studied with a different value of coefficient of friction and normal force. Figures $(12,13$ and 14) demonstrate the same behavior of equivalent stress in (Case 1); this leads to conclude that the frictional force affects the equivalent stress behavior more than the normal force, where it affects the level of the stress [13].

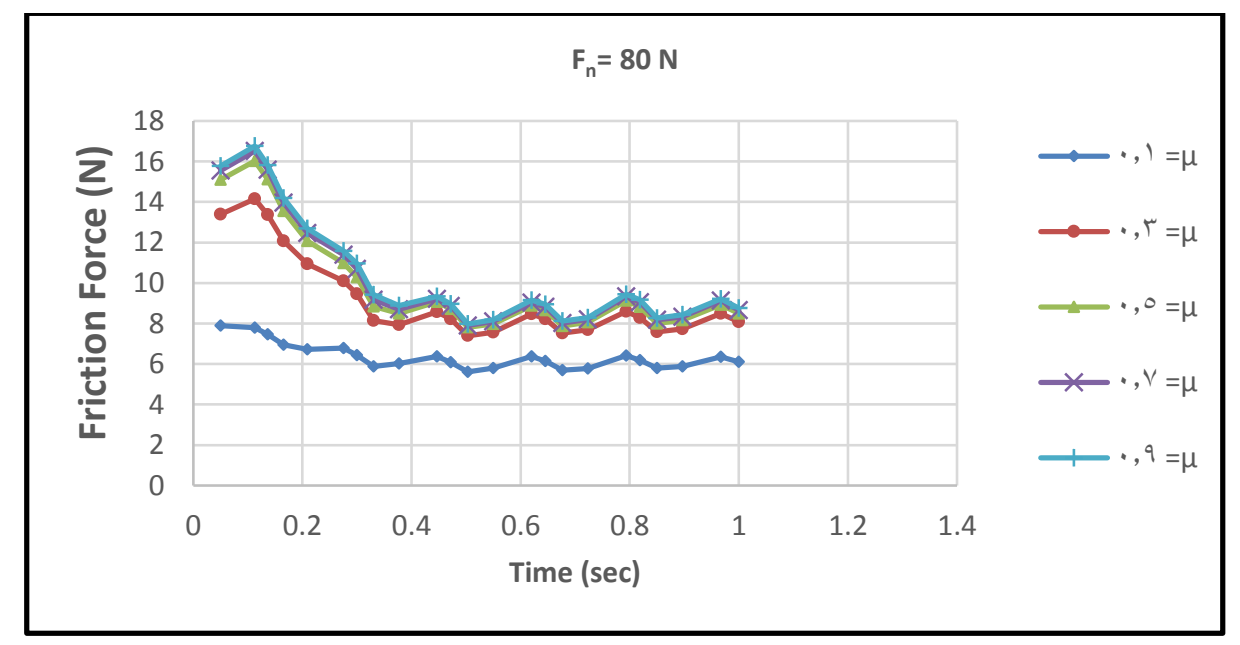

Fig (12) Friction force at normal force $80 \mathrm{~N}$

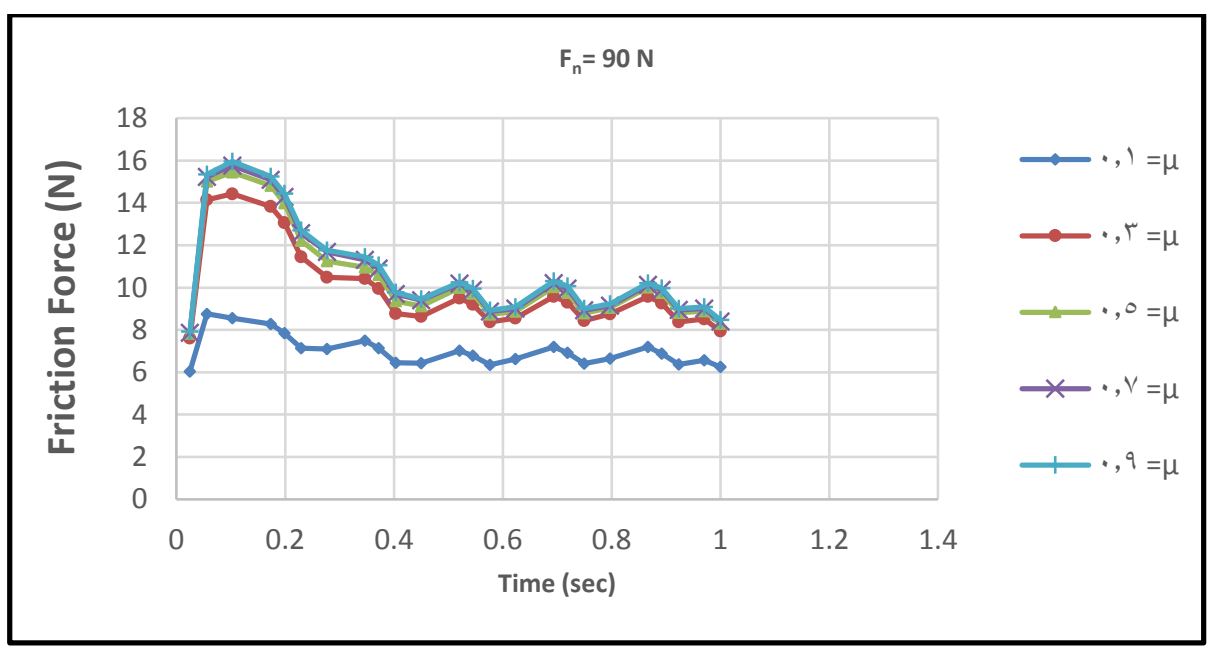

Fig (13) Friction force at normal force $90 \mathrm{~N}$ 


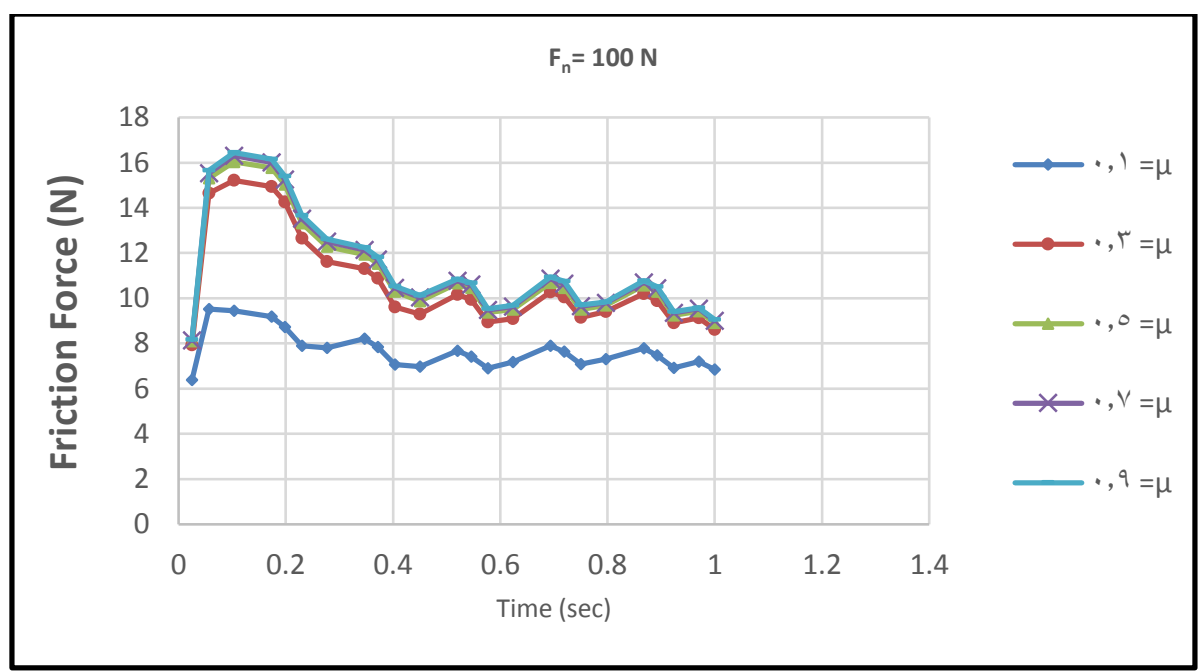

Fig (14) Friction force at normal force $100 \mathrm{~N}$

\section{4 - Case 4}

In this case, the deformation in slipped object was evaluated at the forces $0,80,90$, and $100 \mathrm{~N}$ and coefficient of friction $(\mu=0.9)$ by monitoring the deformation in the sector length $(a)$.

Table (3) shows the change in area and sector length (a) when applying the normal force. The results in this table illustrate the increase in deformation at the edge of the object; this is because it's free to deform more than the other parts of slipped object, and this region is deviating from the center of the object due to the slippage effect. In addition, the stick-slip transitions occur because of the rubber, which helps to deform [14].

Table (3): Change in contact area.

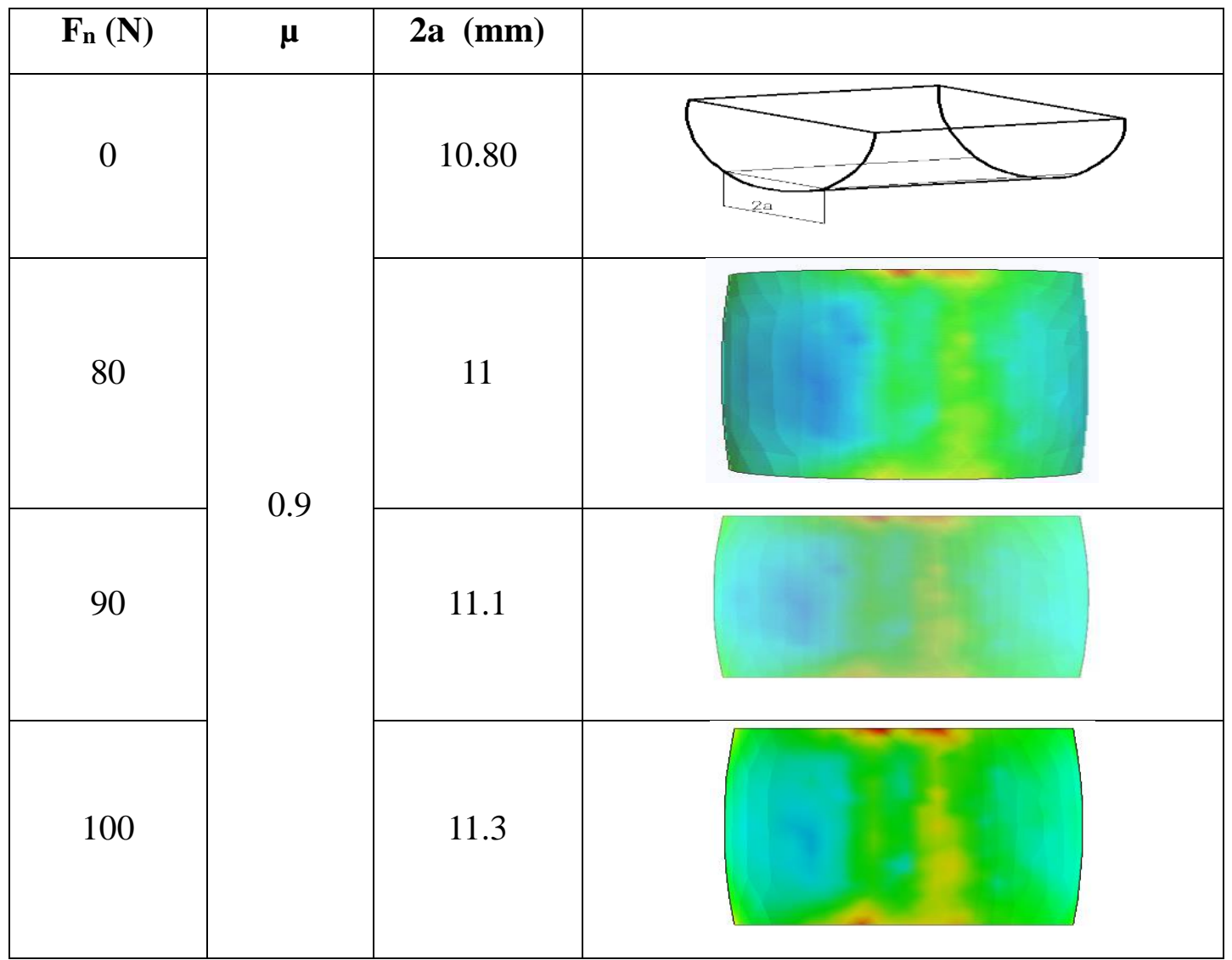




\section{5 -Conclusion:}

From the results of this study, the following conclusions can be drawn:

1- The numerical analysis for the two contacted bodies elucidated good results (Von-Mises stress, Frictional forces), since these results evinced a good agreement with the physical phenomena, like static to kinetic frictional transition mode and slip-stick behavior or friction induced vibration.

2- The slippage influence was found to be the main parameter affecting the results, where this phenomenon can be detected through many methods that depend on the mechanics of contact. Therefore, this study can be contributed in experimental works to detect the slippage occurrence.

3- The decrease in the value of Von Mises stress due to the transition from the value of the static friction to the dynamic friction during the sliding process, which is less than the coefficient of friction, which generates less friction force that will lead to a decrease in the stresses.

4- The frictional force affects the equivalent stress behavior more than the normal force, where it affects the level of the stress.

5- The increase in force with the slipping increases the deformation; especially in the free zone of the contact area, in addition to that the rubber material is deformable.

6- The results displayed that the increase in the deformation is at the edge of the object since it is free to deform more than the other parts of slipped object,

Eventually, the stress distribution monitoring can be achieved through mounting an array of strain gages, which are embedded in the viscoelastic parts.

\section{CONFLICT OF INTERESTS.}

- $\quad$ There are no conflicts of interest.

\section{6 - References}

[1] N. Xydas and I. Kao, "Modeling of Contact Mechanics and Friction Limit Surfaces for Soft Fingers in Robotics, with Experimental Results", The International Journal of Robotics Research, Vol.18, pp. 941-950, 1999.

[2] L. Kogut and I. Etsion, "Elastic-Plastic Contact Analysis of a Sphere and a Rigid Flat", Journal of Applied Mechanics, Vol. 69, pp. 657-662, 2002.

[3] J. K. Ryu, S. Lee, S. Rhim, and J. Choi, "Simulation and Experimental Methods for Media Transport System; Part II, Effect of Normal Force on Slippage of Paper", Journal of Mechanical Science and Technology, Vol. 19, No. 1, pp. 403- 410, 2005.

[4] T. Andre, V. Levesque, V. Hayward, P. Lefevre, and J.- L. Thonnard, "Effect of Skin Hydration on the Dynamics of Fingertip Gripping Contact", Journal of the Royal Society Interface, Vol. 8, pp. $1574-1583,2011$.

[5] B. Chatterjee, and P. Sahoo, "Elastic-Plastic Contact of a Deformable Sphere Against a Rigid Flat for Varying Material Properties under Full Stick Contact Condition", Tribology in Industry, Vol. 33, No. 4, pp. 164 - 172, 2011.

[6] S. H. Bakhy, "Modeling of Viscoelastic Contact and Grasping Stability of Hemi cylindrical Fingertips for Robotic and Prosthetic Hands", Journal of Engineering and Development, Vol. 18, No.5, September, ISSN 1813-7822, pp.106 -133, 2014.

[7] Y. Akiyama, S. Okamoto, Y. Yamada, and K. Ishiguro, "Measurement of Contact Behavior Including Slippage of Cuff When Using Wearable Physical Assistant Robot", Journal of Latex Class Files, IEEE, Vol. 11, 2012.

[8] ASTM D412 Vulcanized Rubber and Thermoplastic Elastomers-Tension, Annual Book of ASTM Standards, Vol. 09.01, 2003.

[9] ASTM, A217 cast steel is an alloy steel formulated for casting. 
[10] O. M. Braun, I. Barel, and M. Urbakh, "Dynamics of Transition from Static to Kinetic Friction", the American Physical Society, 2009.

[11] T. Butlin, and J. Woodhouse, "Sensitivity Studies of Friction - Induced Vibration", Int. J. Vehicle Design, Vol. 51, pp. 238 - 257, 2009.

[12] A. Chaikittiratana, S. Koetniyom, and S. Lakkam, "Static/kinetic friction behavior of a clutch facing material: effects of temperature and pressure", World Academy of Science, Engineering and Technology 66, 2012.

[13] O. M. Braun, I. Barel, and M. Urbakh, "Dynamics of Transition from Static to Kinetic Friction", the American Physical Society, PRL 103, 194301, 2009.

[14] M. Janko1, M. Wiertlewski and Y. Visell, "Contact geometry and mechanics predict friction forces during tactile surface exploration", Scientific Reports8:4868, DOI: 10.1038/s41598-01823150-7, 2018. 


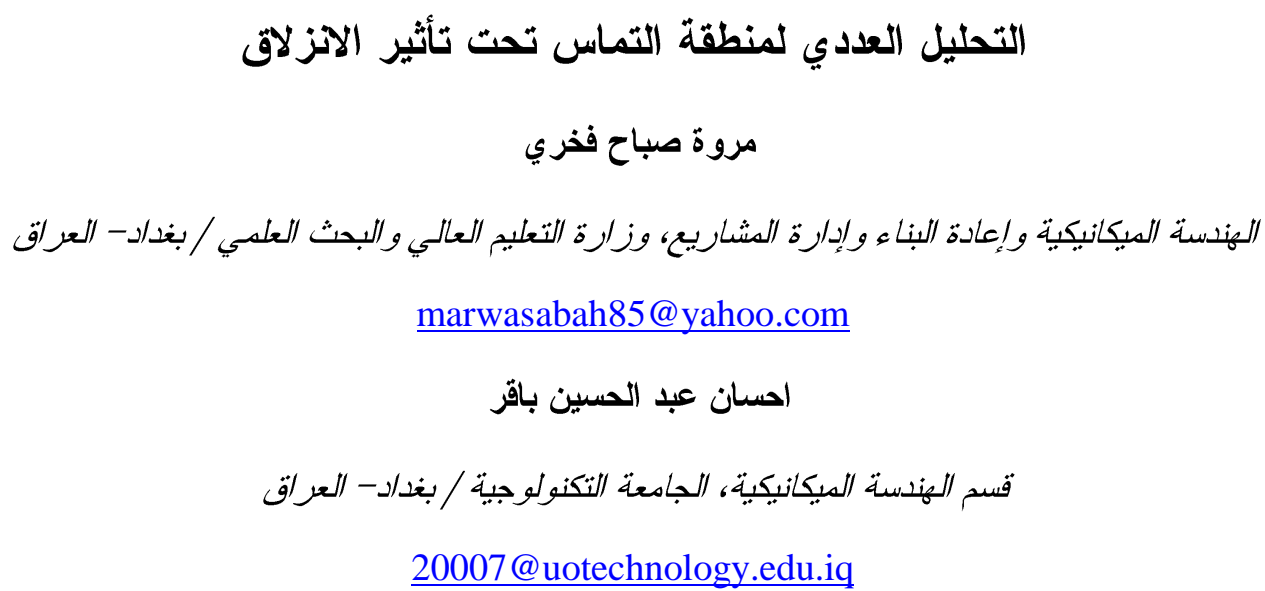

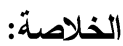

في هذا البحث، تم دراسة منطقة التماس التي نتولد بين جسمين (أحدها سطح مستو و الاخر سطح نصف أسطو اني) تحت

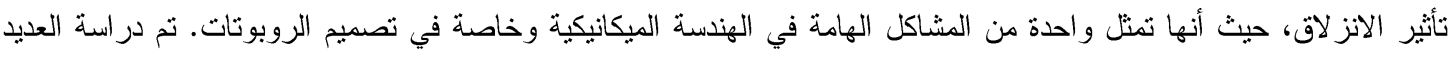

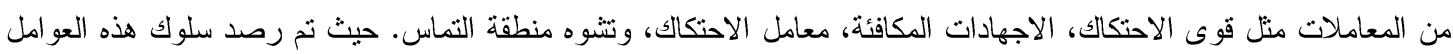
خلال الانز لاق الذي ينم إنثاؤه بين سطح مستو مصنوع من سبائك الحديد الصلب و الجزء الآخر المصنوع من المطاط. أظهرت الآناف

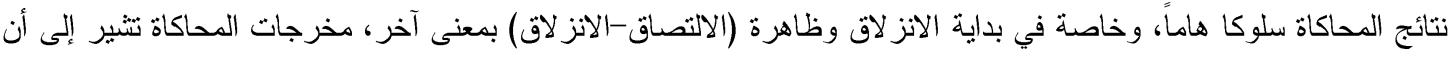

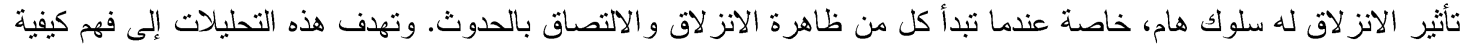

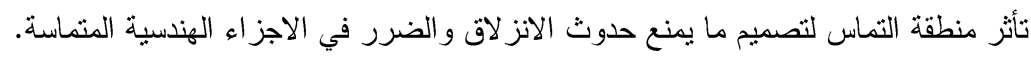
الكلمات الداله: مساحة التماس، ظاهرة الانز لاق، التماس اللزج، تحليل الاجهاد، قوة الاحتكاك. 